Article

\title{
Effect of Mimosa Grafting on Anatomy, Chemical Composition and Tensile Properties of Bamboo Fiber
}

\author{
Shamsun Nahar ${ }^{1,2, *}$ and Mahbub Hasan ${ }^{1}$ \\ 1 Department of Materials and Metallurgical Engineering, Bangladesh University of Engineering and \\ Technology, Dhaka 1000, Bangladesh \\ 2 Bangladesh College of Leather Engineering and Technology, Dhaka 1000, Bangladesh \\ *E-mail: shamshilpi@yahoo.com (Corresponding author)
}

\begin{abstract}
The current study presents systematic and improved methodologies to characterize elementary bamboo fiber grafted with mimosa. For that, control and grafted bamboo culm anatomy was observed under scanning electron microscopy (SEM), chemical analysis was conducted and tensile properties were measured. During surface analysis, smoother surface was found for grafted fiber compared to the control fiber. No significant change in chemical composition was observed after grafting. In this experiment with the increase of span length the value of tensile strength has decreased but the young modulus has increased. The tensile strength of grafted fiber was higher than the control fiber. This is because fiber of larger span length has much larger surface area having more flaws and surface defects, which make the chance of failure larger .Thus it can be concluded that mimosa grafting seems to be useful for stronger control fiber with more reliable results.
\end{abstract}

Keywords: Mimosa, strain to failure, $\alpha$-cellulose, SEM.

ENGINEERING JOURNAL Volume 17 Issue 2

Received 6 August 2012

Accepted 2 January 2013

Published 1 April 2013

Online at http://www.engj.org/

DOI:10.4186/ej.2013.17.2.39 


\section{Introduction}

In the context of challenging environmental issues and a global energy crisis, bio-based materials are attracting increasing levels of research interest, from both academia and industry, because of their numerous advantages: renewable resource usage, low cost, biodegradability, and so on $[1,2]$. The development of biodegradable polymers has been a subject of great interest in materials science for both ecological and biomedical perspectives. Increasing awareness of the environmental damage caused by plastic materials over the last few decades has led to research aimed at producing eco-friendly versions of those plastics [3, 4]. For that polymer matrix composites, such as carbon or glass fiber reinforced plastics have been widely used in industry since they have high strength and modulus [5, 6]. Hemp, flax, sisal, jute etc have been identified as attractive materials for the reinforcement of thermoplastic polymers. They are cheap, abundant and renewable, and have good specific properties due to their low densities [7-10]. Beside them, bamboo fiber can also be used as a potential reinforcement in composite. Bamboo is an abundant natural resource in Asia, and its overall mechanical properties are comparable to those of other fibers. Bamboo has a great potential to be used as a reinforcing agent in polymeric composites. Such composites can be successfully used as consumer durable goods and for less-intensive load-bearing application. Furthermore, bamboo grows to its mature size in only 6-8 months, whereas wood takes about 10 years. Shao et el. [11], Papadopoulos et el. [12] and Kongkeaw et el. [13] worked on bamboo fiber for composite preparation. In natural fiber, presence of hydroxyl and polar groups lead to weak interfacial bonding between fibers and relatively hydrophobic polymers. This is due to pendant hydroxyl and polar groups in various constituents of fiber. As a result hydrophilic natural fibers absorb a large amount of water in the composite leading to failure by delamination from the matrix. Adequate adhesion across the interface can be achieved at desirable levels by better wetting and chemical bonding between fiber and matrix. To make good use of biofiber reinforcement in composites, fiber surface treatment can carried out to obtain an enhanced interface bonding between hydrophilic bamboo fiber and hydrophobic polymer matrixes. Besides such treatments will decrease the moisture absorption and hydrophilic character of bamboo fibers. Surface modification is therefore necessary to obtain better performance of the resulting composite. Kushwaha et el. used silane as interfacial coupling agents to form stable covalent bonds with both the mineral fiber surface and the resin [14]. Chen et al. used cardanol as grafting agent in preparation for better performance of composite. In their experiment isocyanate silane and amino silane were used to modify the surface of bamboo fiber $[15,16]$. In present research mimosa was used for grafting the surface of bamboo fiber. Grafting reaction is a practical technique to improve its dyeability, compatibility and hydrophobicity in economical way conducting chemical modification or polymerization reaction. Grafting enhanced the commercial viability and cost effectitiveness of the material. Man's relationship with plant polyphenols is ancient. Mimosa is vegetable polyphenols tannis, which converted organic substance into stable materials, raised the denaturation temperature, resistance to putrefaction by micro-organisms in the environment. Chemically, mimosa is a polyphenol named 3,4-dihydroxy-2[[(3,4,5-trihydroxybenzoyl)oxa]oxan-2-yl]methol $3,4,5$ trihydroxybenzonzte with molecular weight $36346866 \mathrm{~g} / \mathrm{mol}$ having chemical formula $\mathrm{C}_{27} \mathrm{H}_{24} \mathrm{O}_{18}$. In mimosa there are $11 \mathrm{H}$-bond donor which have been shown in Fig. 1. Mimosa can scavenge carcinogenic and mutagenic oxygen free radical which will be bonded with hydroxyl of cellulosic fiber. As a result cellulose can be able to stabilise against putrefaction, rendering it resistance to biochemical degradation [17, 18]. In present research control fiber was grafted with mimosa and its effect on anatomical, chemical composition and tensile properties were evaluated. It seemed that grafting process can enhance the mechanical properties of bamboo, which in turn can be used for preparing better bio-fiber reinforced composites.

\section{Experimental Method}

\subsection{Materials}

Control fiber was extracted from culms of bamboo plants. The fiber was extracted by steam exploration out of the Bambosa vulgaris species, which is available in Bangladesh. Before test, control fiber was visually selected in order to verify the absence of defects along the length of the fiber. Mimosa was purchased from local market in Bangladesh. All chemicals used in present research were of analytical grade. Chemical structure of mimosa is shown in Fig. 1. 


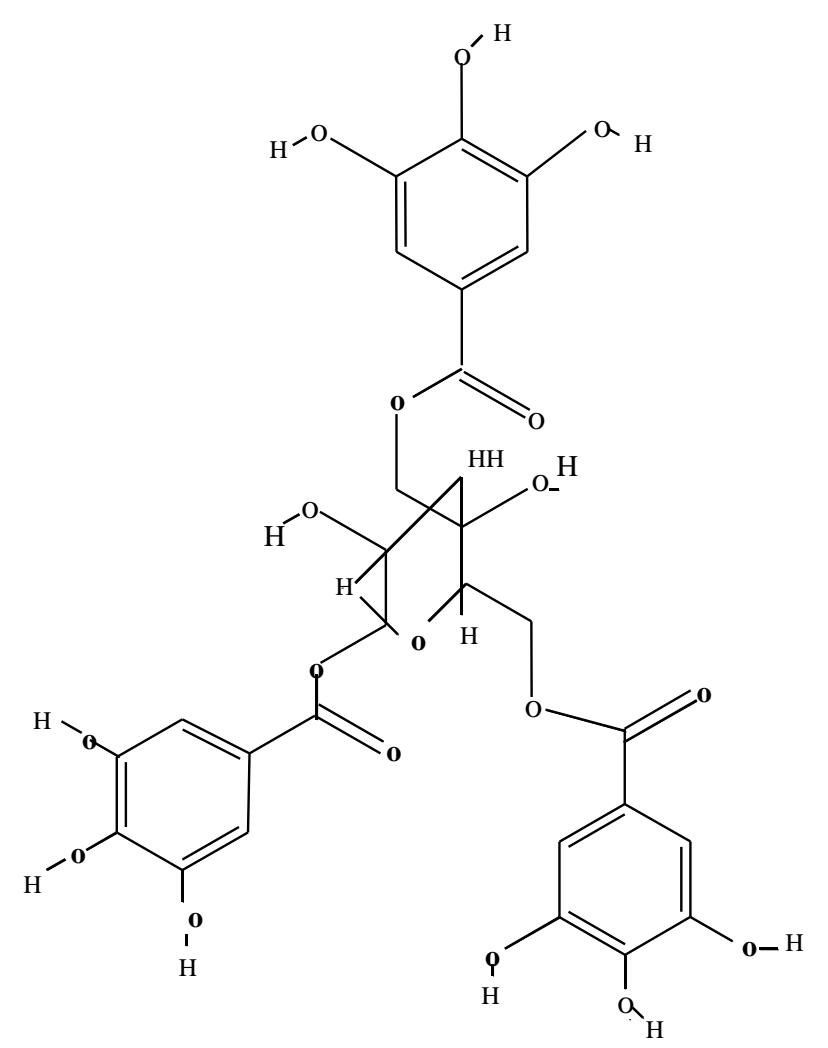

Fig. 1. Chemical structure of mimosa [19].

\subsection{Chemical Treatment of Bamboo Fiber}

The control fibers were initially collected and cleaned. For chemical treatment, a solution of $8 \%$ mimosa with few drops of $\mathrm{H}_{2} \mathrm{SO}_{4}$ was prepared to maintain initial $\mathrm{pH}$ of 4-4.5. Bamboo fiber was taken into the prepared solution and shaken for 3 hours. After 3 hours reaction, the fibers were washed properly in distilled water. Fibers were then dried and stored in dry container.

\subsection{Morphological Study}

The anatomy of bamboo, both control and mimosa treated, culm and cell was observed using scanning electron microscope (XL 30 Philips, Netherland). Diameter of the fiber used for tensile test was also measured from SEM. The samples were made conductive by applying a gold coating using sputtering technique. Thin gold coating caused the electrons to interact with the inner atomic shells of the sample.

\subsection{Chemical Analysis}

In order to determine chemical composition (holocellulose, alpha-cellulose, Klason lignin, hot water extractives and ash) of control and grafted fiber sample, the internodes of each height were cut into small strips with razor blade. The strips were small enough to be placed to ground in a Wiley mill. The material was then placed in a shaker with sieves to pass through a no. 40 mesh sieve $(425-\mu \mathrm{m})$, yet retained on a no. 60 mesh sieve $(250-\mu \mathrm{m})$. The resulting material was then placed in glass jars for chemical analysis. All tests were conducted using ASTM standards [20-25].

\subsection{Tensile Test}

Tensile test of control fiber was carried out using an Instron universal testing machine (Model no3369) by varying span length $(5 \mathrm{~mm}, 10 \mathrm{~mm}, 15 \mathrm{~mm}, 25 \mathrm{~mm}$ and $35 \mathrm{~mm})$ of both control and grafted fiber. The sample preparation is shown in Fig. 2. The cross-head speed and load cell used were $1 \mathrm{~mm} / \mathrm{min}$ and $200 \mathrm{~N}$ respectively. Samples which had broken near the edge of the clamps were excluded from the analysis. The 
isolated fibers were conditioned at $20 \pm 2^{\circ} \mathrm{C}$ and $65 \pm 2 \%$ relative humidity before temporarily fixed on the paper frame with adhesive tape. A droplet of glue was applied on the centre of both sides of the hole along the length of card.

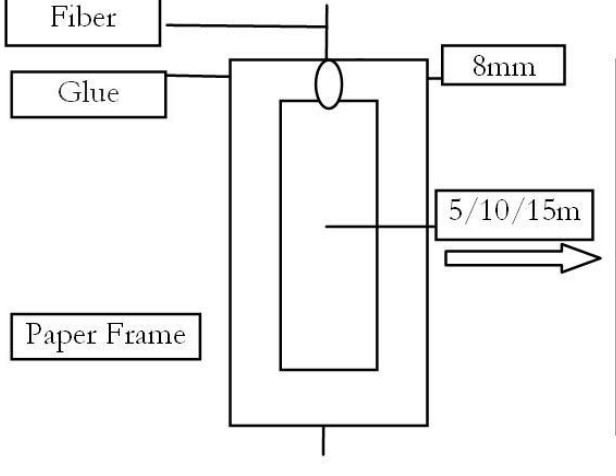

(a)

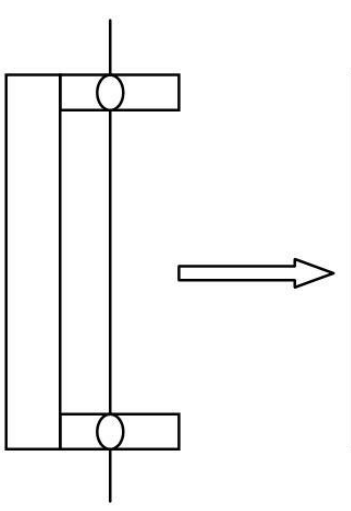

(b)

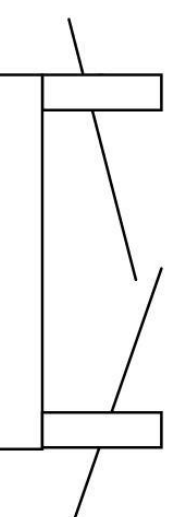

(c)

Fig. 2. Set-up of single fiber testing: (a) specimen mount; (b) test specimen on the paper frame; (c) broken fiber.

The tensile strength was calculated using following formulas:

Tensile Strength, $\quad \sigma=\frac{\mathrm{F}_{\max }}{\mathrm{A}}$

where $F_{\max }$ is maximum force and $A$ is cross sectional area.

The Young's Modulus and strain to failure was measured from the stress-strain curve. During tensile test, some slippage portions always occur. Large span length minimizes the slippage portion more compare to smaller ones. Thus Young's modulus found was higher for larger which was not desired. So correction was required for Young's modulus values. Young's modulus was corrected by using the following steps:

$$
\frac{\Delta \mathrm{l}_{\text {total }}}{\text { Test length }}=\frac{\Delta \mathrm{l}_{\text {fiber }}}{\text { Test length }}+\frac{\Delta \mathrm{l}_{\text {nonfiber }}}{\text { Test length }}
$$

where $\Delta \mathrm{l}_{\text {total }}$ is the measured displacement of the clamps, $\Delta \mathrm{l}_{\text {fiber }}$ is the elongation of the fiber and $\Delta \mathrm{l}_{\text {nonfiber }}$ is the displacement caused by slippage and test set up compliance.

A correction process was adopted to determine the non fiber displacement. The fiber displacement $\Delta \mathrm{l}_{\text {total }}$ was measured and at a certain stress in the linear part of the stress-strain curve was calculated. $(\Delta \mathrm{l}$ fiber/test length) was calculated by dividing the same chosen stress by the estimated the e-modulus for an infinity long test length, in other word the extrapolated modulus from an Young's modulus in function of $(1 /$ span length $)$ curve at $(1 /$ span length $)=0$.

$$
\frac{\Delta \mathrm{l}_{\text {non fiber }}}{\text { test length }}=\frac{\alpha \mathrm{F}}{\text { test length }}=\frac{\sigma \mathrm{A} \alpha}{\text { test length }}
$$

where $\mathrm{F}$ is the load put on the fiber, $\mathrm{A}$ is the cross-sectional area, $\sigma$ is the stress (in the linear portion of the stress strain curve) $\alpha$ the factors that estimated the influenced of slippage and the test setup compliance. So for every tested fiber $\alpha$ can be calculated:

$$
\alpha_{i}=\frac{\Delta \mathrm{l}_{\text {total }, \mathrm{i}}-\Delta \mathrm{l}_{\text {fiber }, \mathrm{i}}}{\mathrm{F}_{\mathrm{i}}}
$$

All $\alpha$-values were plotted in function of span length and by linear regression, an estimated of the $\alpha$ value for each test length can be determined ( $\alpha$ test length) for each type of fiber. With this estimated value for $\alpha$ the corrected strain can be calculated:

$$
\text { Corrected Strain }=\frac{\Delta 1_{\text {fiber }} \mathrm{i}}{\text { test length }}=\frac{\Delta 1_{\text {total }} \text { i }}{\text { testlength }}-\frac{\text { atest length } F_{\text {i }}}{\text { test length }}
$$

Young's modulus was finally determined by drawing the stress in function of corrected stress-strain curve. 


\section{Results \& Discussion}

\subsection{Morphological Study}

In present research, anatomy and cell wall was observed under SEM. Fig. 3(a) and Fig. 3(b) represent the surface and cross-sectional area of control fiber respectively, while Fig. 4(a) and Fig. 4(b) represent the surface and cross-sectional area of grafted fiber respectively. The inner layer is wrapped by sclerenchyma cells. In lacuna, elements in bamboo are easily permeable. The structure of a bamboo culm transverse section characterized by numerous vascular bundles embedded in the sclerenchyma tissue and parenchymatous ground tissue. The parenchyma cells are mostly thin-walled and connected to each other by numerous simple pits. Pits are located predominantly on the longitudinal walls. But the sclerenchyma cells are thick-walled. Sclerenchyma generally forms packages of fibers below vascular bundles and around the vascular bundle. Sclerenchyma surrounding the first cycle of peripheral vascular bundles are not interrupted by interfascicular parenchyma. Surface of control and grafted fiber was under the SEM. The surface of the grafted fiber sample was smoother compared to the untreated bamboo fiber. When the bamboo fiber was grafted with mimosa, in the transverse section, parenchymatous ground tissue was found thicker than the control fiber. As there is no significant change in chemical composition so the change was may be in the cellulosic chain. May be mimosa have been deposited in the cellulose chain. As mimosa have $11 \mathrm{H}$ - donor for that they formed the covalent bond with cellulose - $\mathrm{COOH}$ to form cellulose stronger.

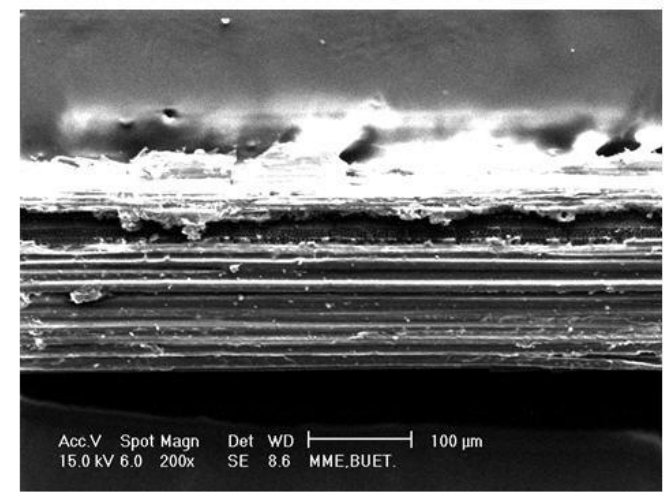

(a)

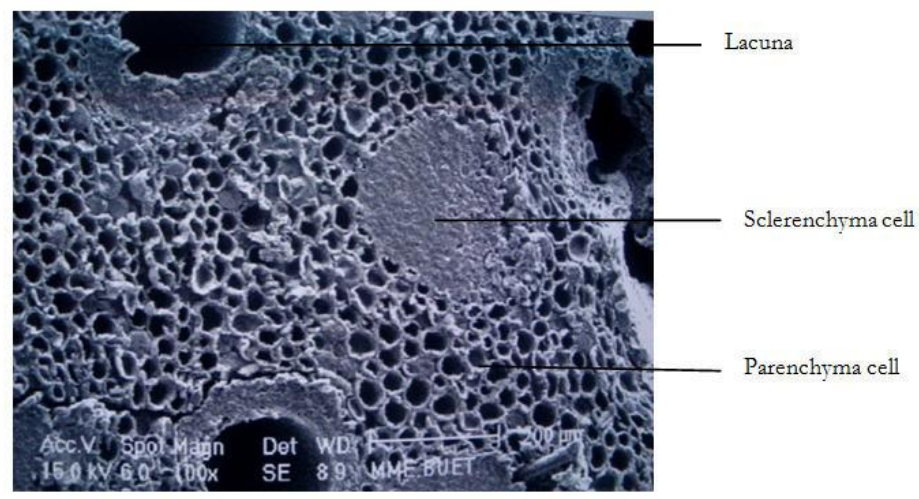

(b)

Fig. 3. SEM of (a) cell wall and (b) cross-sectional area of control bamboo fiber.

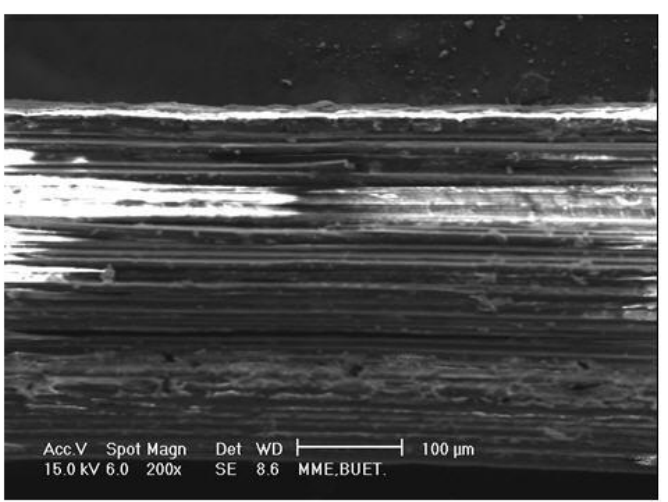

(a)

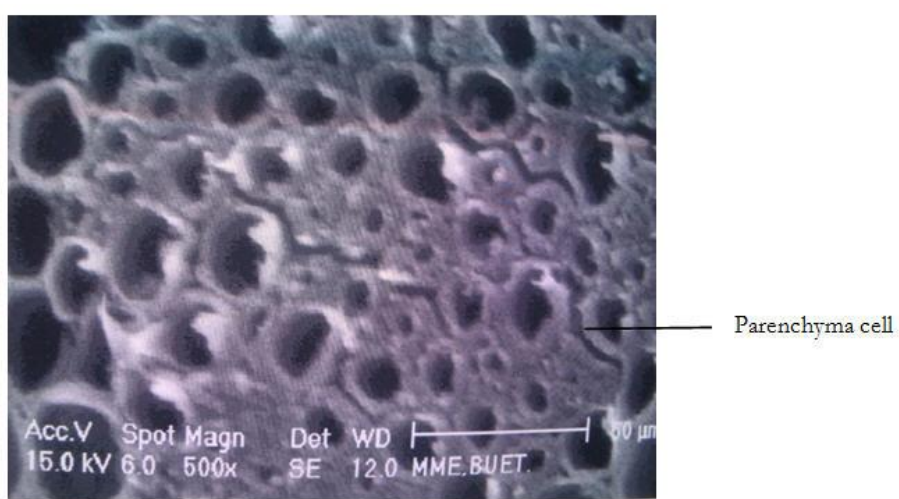

(b)

Fig. 4. SEM of (a) cell wall and (b) cross-sectional area of mimosa grafted bamboo fiber.

\subsection{Chemical Analysis}

The results of chemical analysis of control and grafted bamboo fiber are listed in Table 1. In this processes $14.03 \%$ mimosa was grafted. Li worked on Phyllostachys pubescens bamboo and found $5.14 \%$ hot water solubility, $22.11 \%$ lignin, $70.84 \%$ holocellulose, $47.30 \% \alpha$-cellulose, $1.94 \%$ ash [26]. Ghoshal et al. worked 
on bamboo fiber and found $60 \%$ cellulose and 32\% lignin [16]. During present chemical analysis, alpha cellulose was found to be $50.23 \pm .18 \%$ indicating that homopolysacsride consist of $\beta$-D-glucopyranose linked together by $\beta, 1-4-$ linkage. Each cellulose monomer contained three hydroxyl groups that were able to form hydrogen bond for crystalline packing governing the tensile properties of cellulose of bamboo [2730]. No significant change in chemical composition was observed after grafting.

Table 1. Chemical composition of original and mimosa treated bamboo sample.

\begin{tabular}{cccccccc}
\hline Sample & $\begin{array}{c}\text { Hot Water } \\
\text { Soluble } \%\end{array}$ & $\begin{array}{c}\text { Moisture } \\
\%\end{array}$ & $\begin{array}{c}\text { Lignin } \\
\%\end{array}$ & $\begin{array}{c}\text { Holocellulose } \\
\%\end{array}$ & $\begin{array}{c}\alpha \text {-cellulose } \\
\%\end{array}$ & $\begin{array}{c}\text { Hemicellulose } \\
\%\end{array}$ & $\begin{array}{c}\text { Ash } \\
\%\end{array}$ \\
\hline $\begin{array}{c}\text { Original } \\
\text { bamboo }\end{array}$ & $5.07 \pm 0.06$ & $12.33 \pm 0.56$ & $23.91 \pm 0.58$ & $67.08 \pm 0.17$ & $50.23 \pm 0.18$ & $16.85 \pm 0.09$ & $1.38 \pm 0.05$ \\
$\begin{array}{c}\text { Mimosa } \\
\text { treated } \\
\text { bamboo }\end{array}$ & $4.30 \pm 0.03$ & $11.15 \pm 0.55$ & $22.41 \pm 0.32$ & $67.67 \pm 0.12$ & $50.93 \pm 0.18$ & $16.94 \pm 0.09$ & $0.47 \pm 0.02$ \\
\hline
\end{tabular}

\subsection{Tensile Properties}

The tensile strength of control single fiber for different span length is shown in Fig. 5, while Fig. 6 shows average the tensile strength of control and grafted single fiber. Tensile strength decreased with increase in fiber span length. This is because fiber of larger span length has much larger surface area having more flaws and surface defects, which make the chance of failure larger. However the tensile strength of mimosa treated fiber was higher than control fiber. The corrected and uncorrected Young's modulus values for both control and mimosa grafted fiber are shown in Fig. 7 and Fig. 8 respectively. Uncorrected Young's values increased with increase in span length. This may be due to slippage and test setup. The slippery portion is higher for smaller span length compared to higher span length. The uncorrected extrapolated Young's modulus for infinitely long fiber was $35.2 \mathrm{GPa}$ for control fiber and $44.45 \mathrm{Gpa}$ for grafted fiber. Strain to failure against span length for control and grafted fiber are shown in Fig. 9 and Fig. 10 respectively. With increasing the fiber length, the strain failure decreased due to more weaknesses and earlier break.

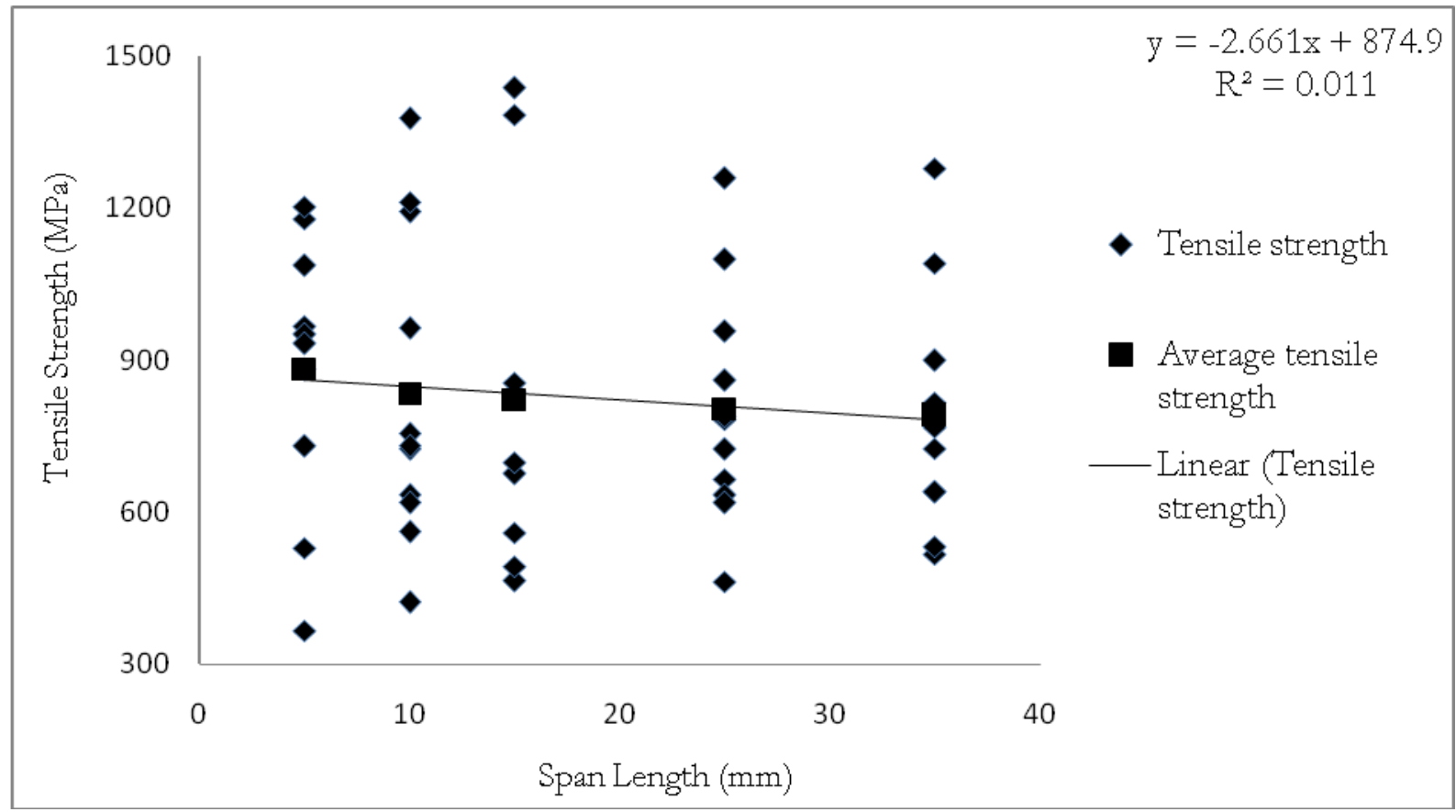

Fig. 5. Tensile strength as a function of fiber span length for control fiber. 


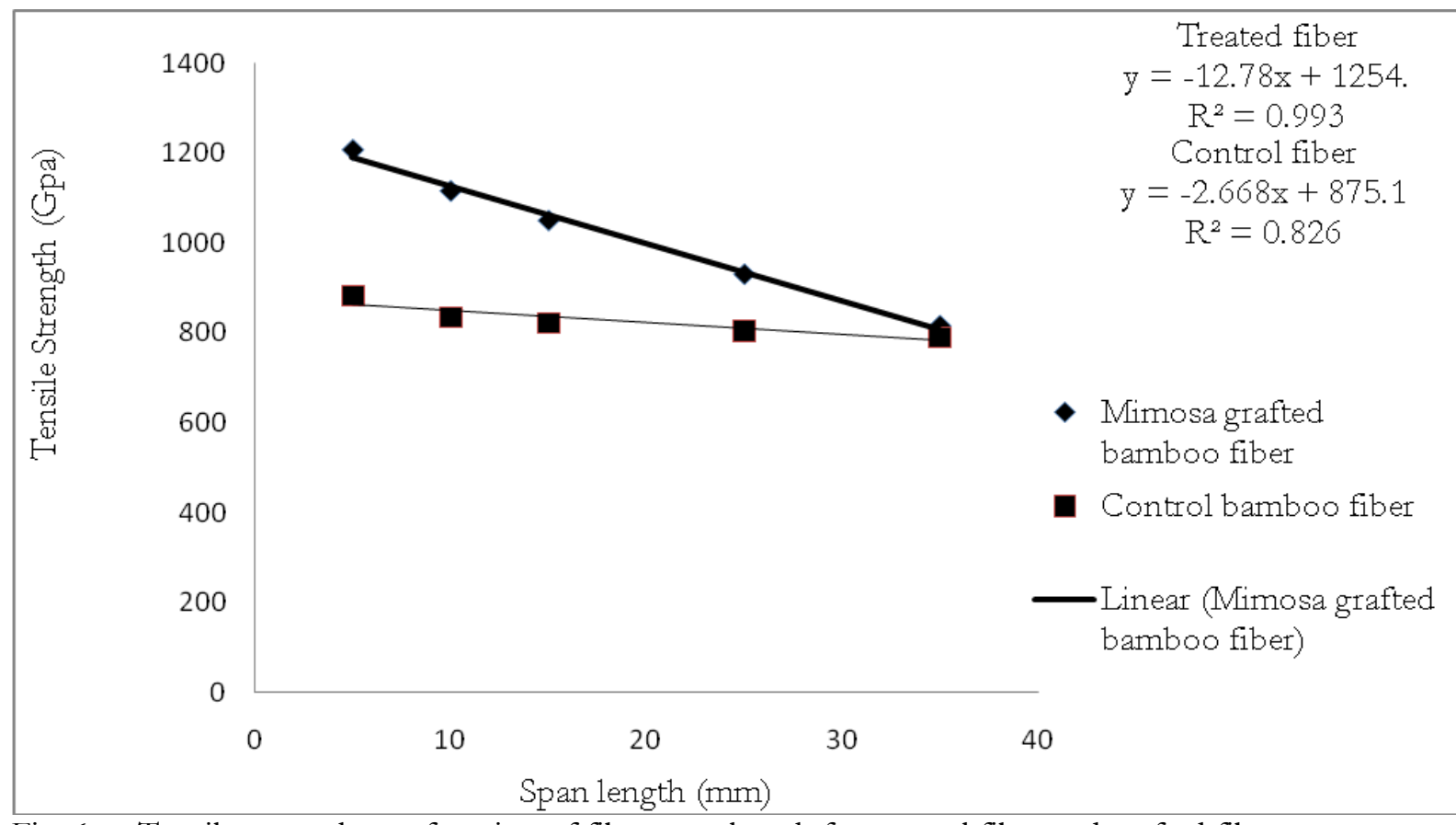

Fig. 6. Tensile strength as a function of fiber span length for control fiber and grafted fiber.

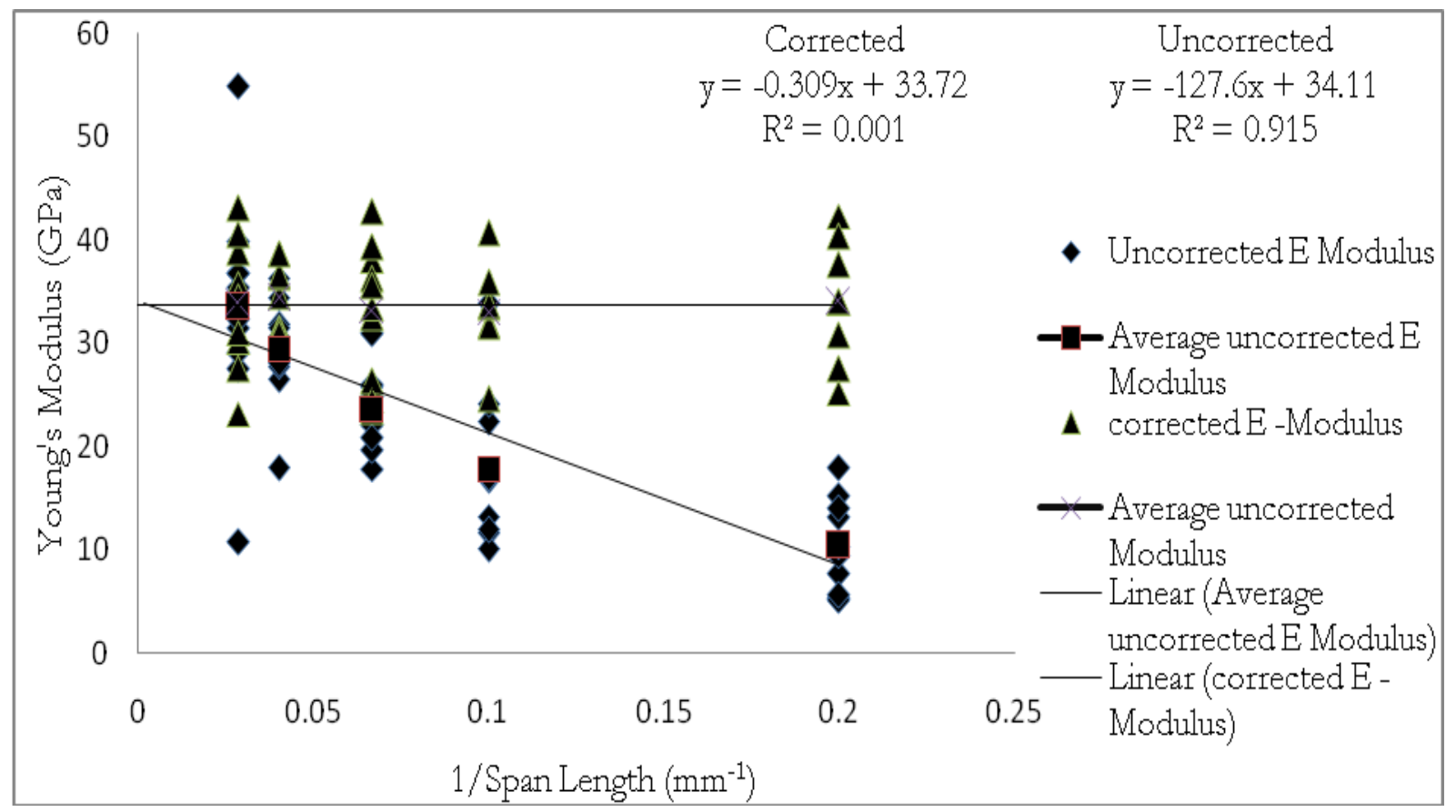

Fig. 7. Uncorrected and corrected Young's modulus vs span length for control fiber. 


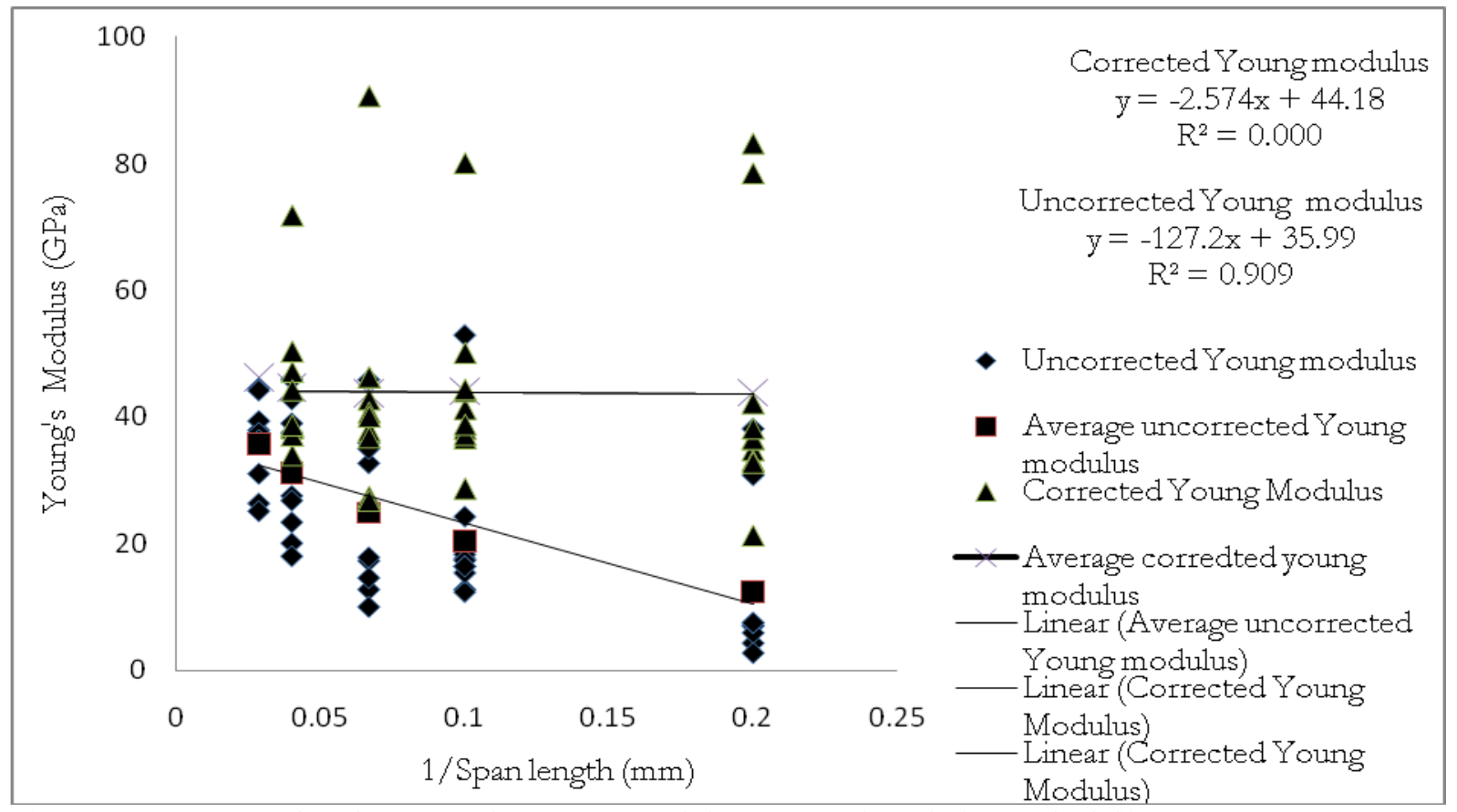

Fig. 8. Uncorrected and corrected Young's modulus vs span length for grafted fiber.

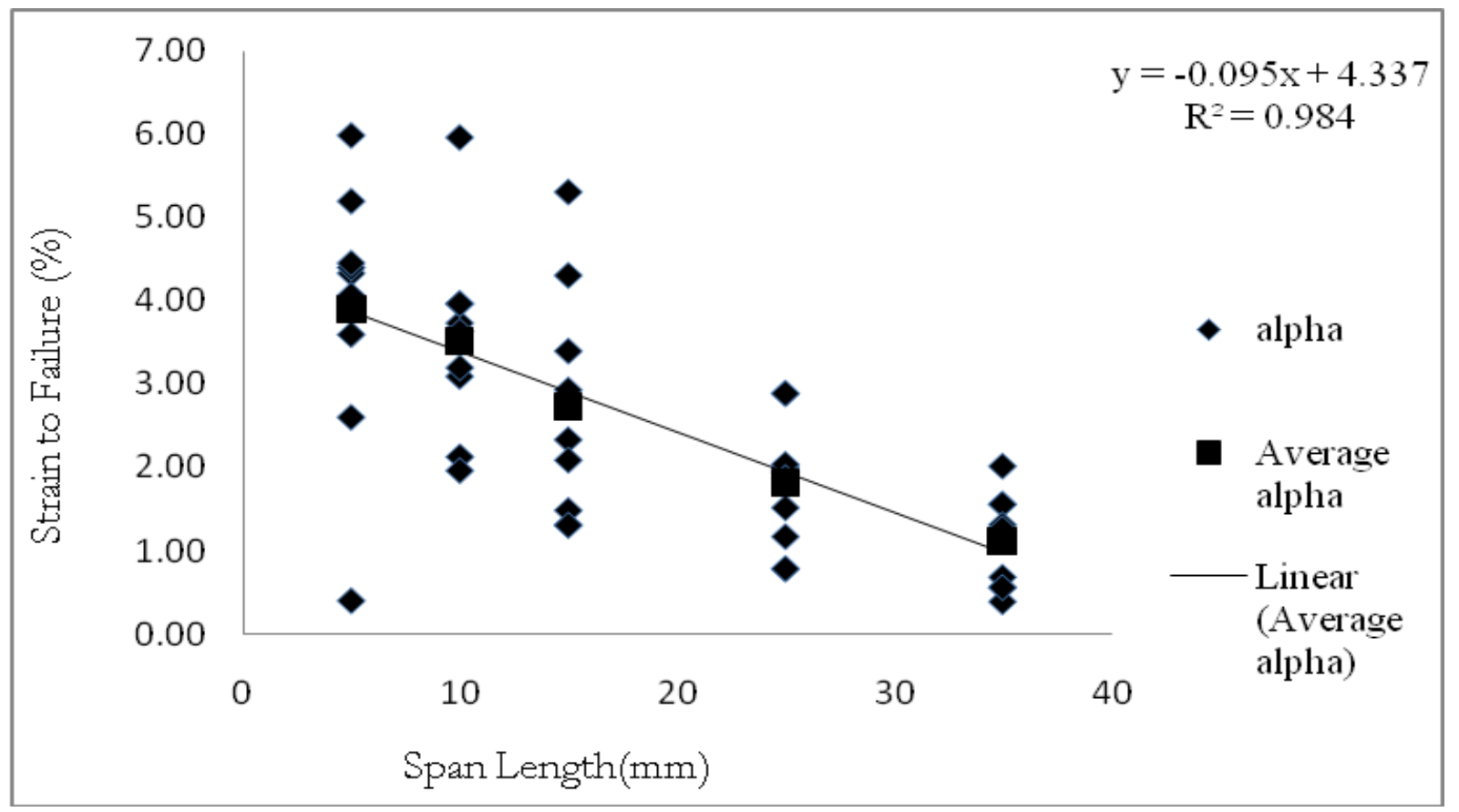

Fig. 9. Strain to failure as a function of span length for control fiber. 


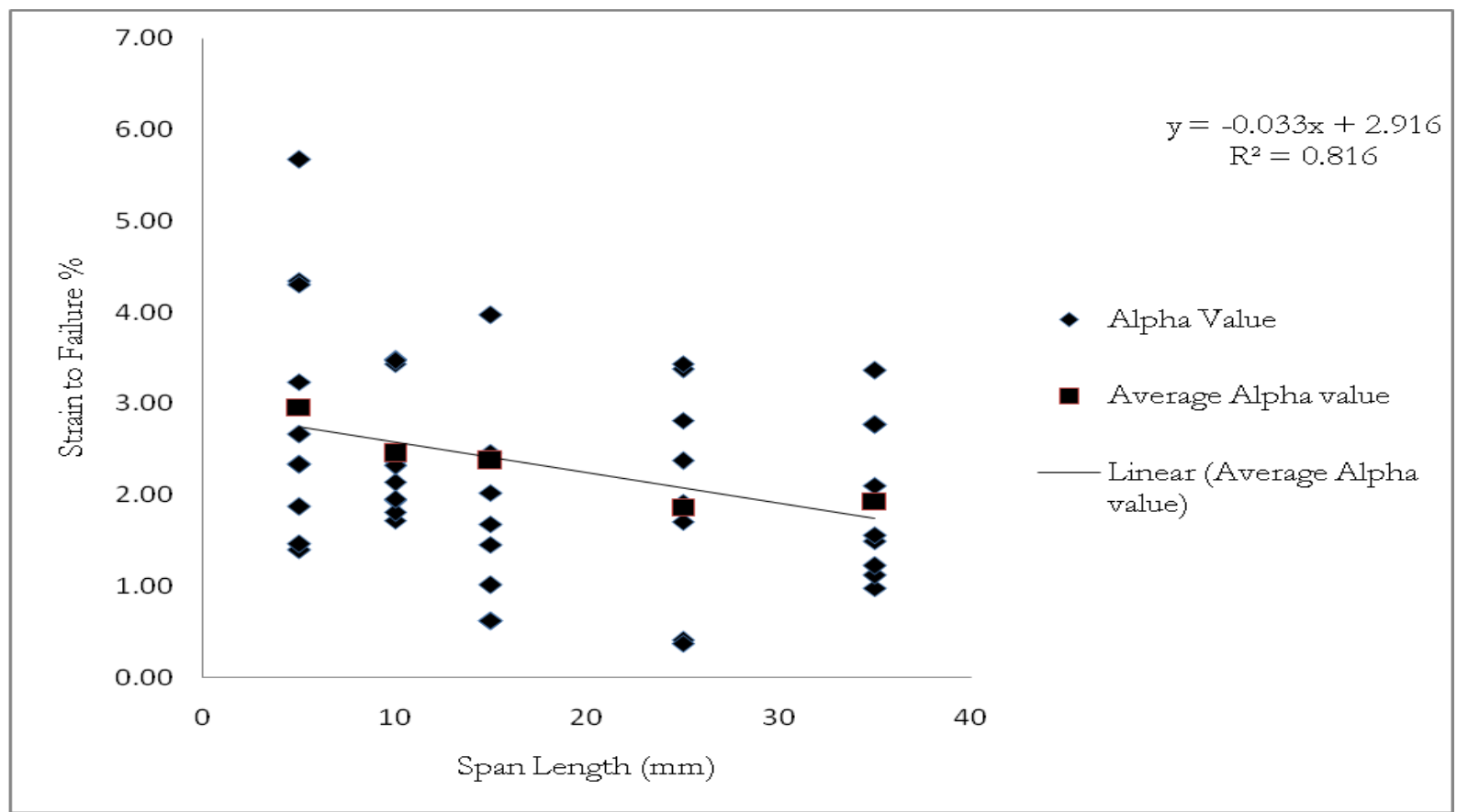

Fig. 10. Strain to failure as a function of span length for grafted fiber.

From SEM, it was observed that the anatomical features directly affect physical and mechanical properties of bamboo. To understand the properties, it is important to study its anatomical characteristics. In circular cross section, most bamboos are found hollow. Bamboo culm comprises about $40 \%$ fibers. Mimosa might react with cellulose via hydrogen bonds resulting in covalent bond. May be for this fixation reaction, 2-4\% mimosa did not removed even in organic solvent. As a result cellulose did not revert to raw condition. In Fig. 1, the proximity of the aromatic nuclei in the mimosa structure means that free radical oxidative bond rearrangement can take place easily. As a result mimosa can react with cellulose to form regular arrangement. Fiber percentage is higher, which contributed to its superior slenderness and strength. Most fibers have a thick poly-lamellate secondary wall. Fibers in bamboos are either grouped in bundles or sheaths around the vascular bundle. This gives the high tensile strength to the bamboo fiber. For that, tensile strength of different span length fiber was measured. It was found that tensile strength decreased with increasing the fiber span length due to multicellular structural flaws, which broke the fiber easily. Uncorrected Young's modulus was dependent on span length. As Young's modulus should be independent of span length, a correction for Young's modulus values was conducted. After calculation it was found that that modulus was independent of span length. [18].

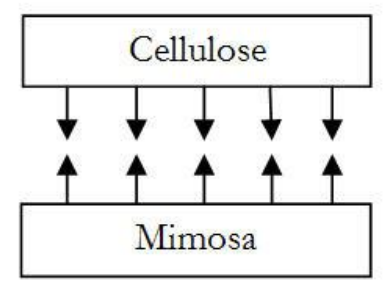

A

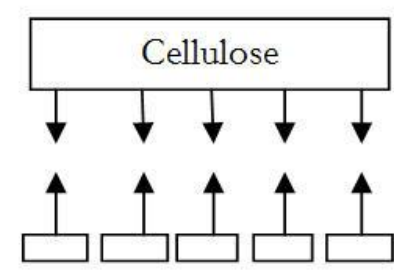

B

Fig. 11. Symmetric bonding diagram of cellulose and mimosa, A is more stable than B.

In longitudinal direction, tensile strength and Young's modulus was dependent on the cell wall, which was assumed to positively correlated to the content of cellulose and lignin. In grafting of mimosa, it makes bond with cellulose with $11-\mathrm{H}$ of mimosa. Mimosa is a bigger molecule containing several molecular active reactive sites which are attached with cellulose. A symmetric representation of grafting of mimosa and cellulose has shown in Fig. 11. As mimosa is a long chain aromatic molecule aggregating for that this mimosa is containing several reactive groups may lead to a more stable compound. This compound is more 
stable compared to equivalent number of small ones each having one reacting group. Symmetric representation is shown in Fig. 11.

Figure 12 represents the possible attaching way of mimosa and cellulose. Cellulose fibers are crystallizing in that way. May be for this reason cellulose fiber is showing more tensile strength and Young's modulus is bamboo fiber. From present study it can be concluded that chemical composition and anatomy are correlated to tensile properties.
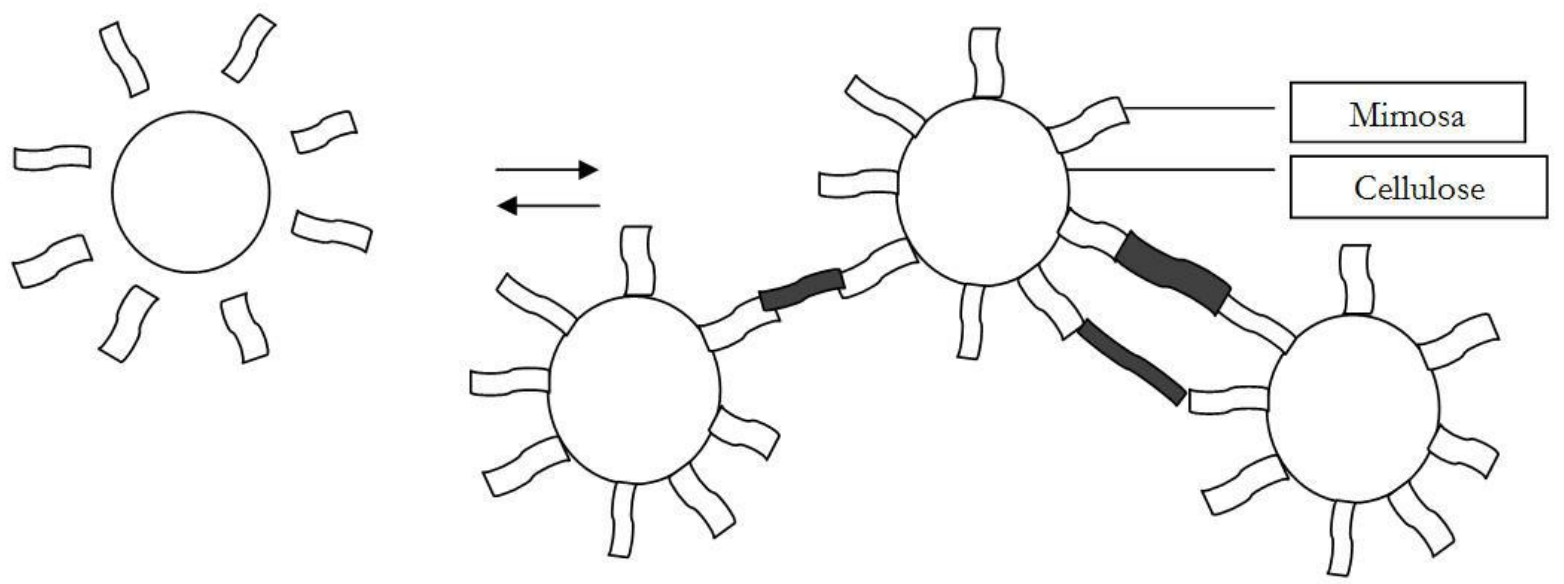

Fig. 12. A possible attaching way of bonding of mimosa and cellulose.

\section{Conclusions}

Depending on anatomical and mechanical properties, grafted fiber can be used for making light weight composites. The Young's modulus of grafted fiber was found to be high compared to other control fibers. The sclerenchyma cell played dominant role on cell properties of meso bamboo. This may be due to the interactions between the components in bamboo. It was observed that mimosa has played as tannins in bamboo fiber. Having higher molecular weight of mimosa, it may be become to a stable cellulosic compound. The tensile strength and Young's modulus increased, which is the desirable properties of reinforcement in composite when the bamboo fiber was grafted with mimosa. It can be concluded that the control fiber grafted with mimosa can be used as biodegradable grafting agent to obtain desirable result for composite.

\section{References}

[1] X. Chen, Q. Guo, and Y. Mi, "Bamboo fiber-reinforced polypropylene composites: A study of the mechanical properties” J. of App. Polym. Sci., vol. 69, pp.1891-1899, 1998.

[2] R. A. Khan, A. J. Parsons, and I. A. Jones, "Preparation and characterization of phosphate glass fibers and fabrication of poly(caprolactone) matrix resorbable composites", J. of Reinf. Plast. Comp., vol. 29, no. 7, pp. 1078-1088, 2010.

[3] A. P. Deshpande, M. B. Rao, and C. L. Rao, "Extraction of bamboo fibers and their use as reinforcement in polymeric composites," J. of Appl. Polym. Sci, vol. 76, pp. 83-92, 2000.

[4] Y. Huang, H. Liu, P. He, L. Yuan, H. Xiong, Y. Xu, and Y. Yu, "Nonisothermal crystallization kinetics of modified bamboo fiber/PCL composites," J. of Appl. Polym. Sci, vol. 116, pp. 2119-2125, 2010.

[5] S. B. Koradiya, , J. P. Patel, and P. H. Parsania, "The preparation and physic-chemical study of glass, jute and hybrid glass-jute bisphenol-c-based epoxy resin composites," Polym. Plast. Tech. and Engg., vol. 49, no. 14, pp. 1445-1449, 2010.

[6] M. Jacob, S. Thomas, and K. T. Varughese, "Mechanical properties of sisal/oil palm hybrid fiber reinforced natural rubber composite," Comp. sci. and Tech., vol. 64, pp. 955-965, 2004.

[7] M. A. Khan, J. Islam, M. A. Rahman, R. A. Khan, and T. Islam, "Study on the effect of urea on the mechanical and morphological properties of jute/gelatin composites," Polym. Plast. Tech. and Engg., vol. 49, no. 9, pp. 885- 891, 2010. 
[8] M. Fan, "Chracterization and performance of hemp fibers: Factors influencing tensile strength," Bioresource, vol. 5, no. 4, pp. 2307-2322, 2010.

[9] J. Li, S. Li, H. Wan, Y. Yang, and G. Gou, "Preparation of lignin based composite and its preparation," Bioresource, vol. 6, no. 2, pp. 1532-1542, 2011.

[10] K. Dey, N. Sharmin, R. A. Khan, S. Nahar, A. J. Parsons, and C. D. Rudd, "Effect of iron phosphate glass on the physico-mechanical properties of jute fabric-reinforced polypropylene-based composites," Journal of Thermoplas Composite Materials, vol. 24, no. 5, pp. 695-711, 2011.

[11] Z. P. Shao, C. H. Fang, S. X. Huang, and G. L. Tian, "Tensile properties of Moso bamboo (Phyllostachys pubescens) and its components with respect to its fiber-reinforced composite structure," Wood Sci Technol., vol. 44, pp. 655-666, 2010.

[12] A. N. Papadopoulos, C. A. S. Hill, A. Gkaraveli, G. A. Ntalos, and S. P. Karastergiou, "Bamboo chips (Bambusa vulgaris) as an alternative lignocellulosic raw material for particleboard manufacture," Holz: Roh. Werkst, vol. 62, pp. 36-39, 2004.

[13] P. Kongkeaw, W. Nhuapeng, and W. Thamajaree, "The effect of fiber length on tensile properties of epoxy resin composites reinforced by the fibers of bamboo (Thyrsostachys Siamensis Gamble),"J. of the Microscopy Soci. of Thailand, vol. 4, pp. 46-48, 2011.

[14] P. K. Kushwaha, and R. Kumar, "Studies on water absorption of bamboo-epoxy composites: Effect of silane treatment of mercerized bamboo," J. of Appl. Polym. Sci., vol. 115, pp. 1846-1852, 2010.

[15] Q. Chen, H. Xue, and J. Lin, "Preparation of polypropylene-graft-cardanol by reactive extrusion and its composite material with bamboo powder," J. of Appl. Polym. Sci., vol. 115, pp.1160-1167, 2010.

[16] N. H. Tung, H. Yamamoto, T. Matsuoka, and T. Fujii, "Effect of surface treatment on interfacial strength between bamboo fiber and PP resin," JSME Inter. J., vol. 47, no. 4, pp.561-564, 2004.

[17] T. Covington, "Vegetable tanning," in Tanning Chemistry: The Science of Leather. Cambridge, UK: The Royal Society of Chemistry Publishing, 2011, ch. 13, sec. 13.2, pp. 281-284.

[18] Wikipedia. (2012, June 25). Tannin [Online]. Available: http://en.wikipedia.org/wiki/Tannin

[19] K. H. Gustavson, "The vegetables tannages," The Chemistry of Tanning Process. New York, USA: Academic press Inc., 1956, ch. 5, sec. 1.2, pp. 142-147.

[20] Sampling and testing of wood pulp shipments and testing wood pulp shipments for moisture, TAPPI, USA, T210 cm-93, 1993.

[21] Standard test method for water solubility of wood, USA, ASTM D 1110-56, 1993.

[22] Standard test method for acid insoluble lignin in wood, USA, ASTM D 1106-56, 1996.

[23] Method of test for holocellulose in wood, USA, ASTM D 1104-56, 1978.

[24] Standard test method for a-cellulose, USA, ASTM D 1103-60, 1978.

[25] Standard test method for ash in wood, USA, ASTM D 1102-84, 2001.

[26] X. Li, "Physical, chemical and mechanical properties of bamboo and its utilization potential for bamboo boa manufacturing," M.S. thesis, Louisiana State University, 2004.

[27] M. M. Thwea and K. Liaob, "Durability of bamboo-glass fiber reinforced polymer matrix hybrid composites," Comp. Sci. and Tech., vol. 63, pp. 375-387, 2003.

[28] K. Okubo, T. Fujii, and Y. Yamamoto, "Development of bamboo-based polymer composites and their mechanical properties," Composites: Part A, vol. 35, pp. 377-383, 2004.

[29] J. S. Jue, Z. Q. Shen, and J. S. Hi, "On structure, production, market of bamboo based panel," J. of Fores. Research, vol. 13, no. 2, pp. 151-156, 2002.

[30] G. Siqueira, J. Bras, and A. Dufresne, "Cellulosic bionano composite: A review of preparation, properties and application”, Polym., vol. 2, pp. 728-765, 2010. 
